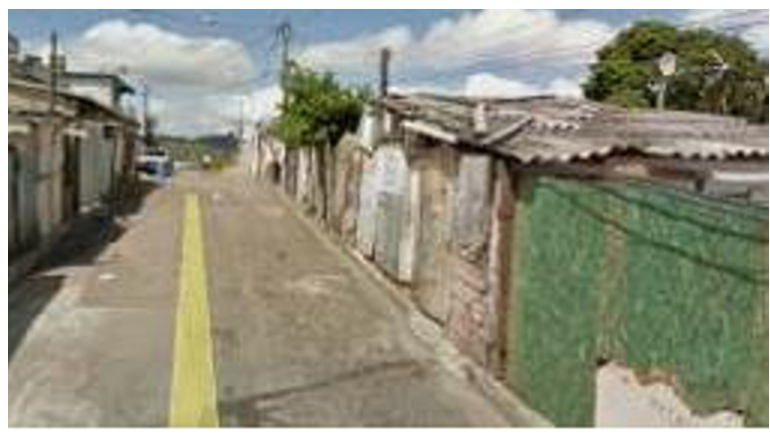

*Arquiteta e Urbanista formada pela UnG Universidade de Guarulhos (SP) no ano de 1999. Pós graduação em Patrimônio Arquitetônico pela PUCC Pontifícia Universidade Católica de Campinas, ano 2003 e mestre em Urbanismo também pela PUCC em 2018. Atua como profissional autônoma desde 2000 e atualmente ministra aulas na UNIP Universidade Paulista em Jundiaí, desde junho de 2014.

**Docente no programa de Pós Graduação em Urbanismo e na graduação em Arquitetura e Urbanismo na Pontifícia Universidade Católica de Campinas. É Pós Doutora (2014) e Doutora pela FAUUSP (Habitat - 2010), onde também se graduou (2001), com

o tema "Projeto de Habitação em Favelas: especificidades e parâmetros de qualidade", 10 lugar no Prêmio lberoamericano de Tesis de Investigación sobre Viviendas Sustentables Infonavit - Redalyc (México 2010) . Possui especialização em Regularização urbanística e fundiária de assentamentos precários pelo Institute of Housing and Urban Development Studies da Universidade Erasmus de Rotterdam (Holanda). Temas de pesquisa: projeto de edificações, qualidade da habitação social, urbanização de assentamentos precários, políticas públicas de habitação, custos da urbanização e padrões urbanís ticos, adensamento popula cional urbano, planejamento e projeto urbano, desenho urbano.

usjt • arq.urb • número 24 | janeiro - abril de 2019

\title{
Urbanização de favelas em Jundiaí - SP: os casos do Jardim São Camilo, Jardim Novo Horizonte, Parque Centenário e Vila Ana
}

Slum upgrading in Jundiaí - SP: the cases of Jardim São Camillo, Jardim Novo Horizonte, Parque Centenário and Vila Ana

Patrícia Rodrigues Samora* e Flávia Tarricone Jimenez **

\section{Resumo}

Este artigo apresenta e analisa a experiência recente de Jundiaí - SP que utilizou recursos Federais dos Programas de Aceleração do Crescimento (PAC) e Minha Casa Minha Vida (PMCMV) para urbanizar assentamentos precários da cidade no período de 2010 a 2017. As intervenções realizadas nas comunidades Jardim São Camilo, Jardim Novo Horizonte, Parque Centenário e Vila Ana demonstram variedade tipológica e de soluções urbanísticas que, vistas conjuntamente, são representativas do trabalho da Fundação Municipal Ação Social (FUMAS) órgão municipal engajado nas questões de habitação de interesse social. A partir da coleta de dados do projeto e da obra das quatro experiências, bem como visitas de campo e entrevista com técnicos da FUMAS, as informações foram sintetizadas em um quadro, que permitiu uma visão de conjunto da política empregada no município, que se revelou acertada em muitos aspectos, mas ainda depende de esforços adicionais para se concretizar. Tendo em vista que o Estatuto das Cidades enfatizou o papel dos municípios no planejamento territorial e setorial da habitação, este caso ilustra como ações assertivas em direção a soluções específicas para as necessidades particulares de cada assentamento podem se beneficiar de recursos federais que não impõem modelos únicos.

Palavras-chave: Assentamentos precários. MCMV. FUMAS.
Abstract

This paper presents and analyses the recent slum upgrading experiences in the city of Jundiaí - Sao Paulo State, from 2010 to 2017, funded by the following federal programs: Programa de Aceleração do Crescimento - Assentamentos Precários and Programa Minha Casa Minha Vida. These actions took place in 4 informal settlements: Jardim São Camilo, Jardim Novo Horizonte, Parque Centenário and Vila Ana. Their urban design and housing architecture are examples of diversity, representative of the work developed by Fundação Municipal de Ação Social (FUMAS), the local office responsible by social housing policy. Based on design information, field visit and FUMAS's technicians interviews, we developed an analytical perspective of the 4 experiences and the housing police implemented. As a result, we argue that most of the solutions were successful but many constraints remained. While the City Statute (2001) empowered the municipality as the leader of the urban development and the responsible for the social housing policy, the support of federal financial resources enable the city to develop unique solutions to each community, shifting the current paradigm of social housing as a single and uniform response to the different housing problems.

Keywords: Informal settlements. MCMV. FUMAS. 


\section{Assentamentos informais em Jundiaí e o contexto da política habitacional e urbana}

Co a promulgação do Estatuto da Cidade, os municípios brasileiros tiveram reforçada a importância legal de planejar seu território, enfrentando suas necessidades habitacionais. Associado a isso, os desdobramentos da Política Federal de Habitação após 2003 e o surgimento de programas como o PAC Urbanização de Assentamentos Precários (2007) com grande volume de recursos, posteriormente complementados com o Programa Minha Casa Minha Vida (2009), permitiram que as ações de urbanização de favelas ganhassem escala e importância na agenda municipal.

Um exemplo de município que se beneficiou desta conjunta é Jundiaí. Situado entre dois importantes eixos rodoviários, as Rodovias Anhanguera e Bandeirantes, próximo aos principais polos econômicos do Estado de São Paulo, possui população de 370.126 habitantes (IBGE, 2010) e é sede do Aglomerado Urbano de Jundiaí (AUJ), que inclui ainda Várzea Paulista, Campo Limpo Paulista, Jarinu, Cabreúva, Louveira e Itupeva.
Semelhante à outras cidades brasileiras, a importância econômica e regional de Jundiaí não foi capaz de produzir um espaço urbano com qualidade para todos seus munícipes, e muitos ainda vivem em assentamentos informais e precários. Conforme o Plano Local de Habitação de Interesse Social de 2015 (JUNDIAI, 2015), Jundiaí possui 24 assentamentos precários, e a demanda por novas moradias na cidade, considerando as necessidades dentro e fora destes assentamentos, foi calculada em 12.627 domicílios. A demanda futura por novas moradias até 2025 é de 7.817 novas unidades. Com relação às necessidades qualitativas nos assentamentos precários, o PLHIS estimou que 398 domicílios demandam urbanização simples, 4.765 necessitam de ações de urbanização complexa e 780 moradias aguardam por regularização fundiária (JUNDIAI, 2015).

Mais recentemente, a revisão do Plano Diretor Estratégico de 2016 (JUNDIAI, 2016) informa que 


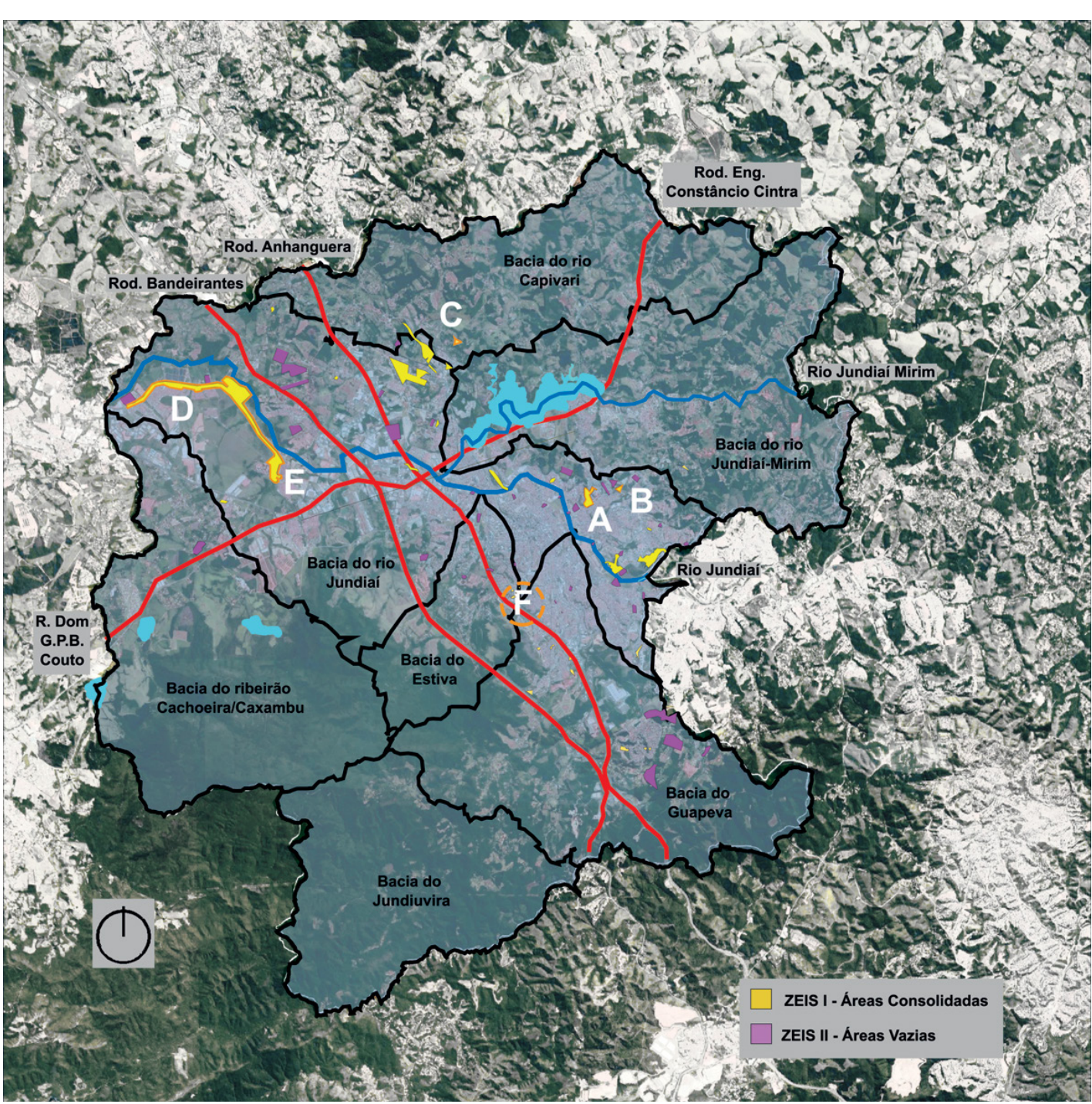

Figura 1. Localização das ZEIS I e II em Jundiaí Fonte: Mapa LEGENDA:

produzido a partir do GEO Portal de Jundiaí a partir do Open A. Jardim São Camilo Street Map. Plano Diretor do município de Jundiaí. geo.jundiai.sp.gov.br, Informações dos mapas de Jundiaí de forma georreferenciada. Adaptado por Dariane S.S. Silva.

usjt • arq.urb • número 24 | janeiro - abril de 2019
B. Cond. Genova e Roma (reassentamento)
C. Parque. Centenário (Jd. Nascente)
D. Jardim Novo Horizonte
E. Área de reurbanização (Jd. Novo Horizonte)
F. Vila Ana

o município possui 68 núcleos urbanos informais, definidos então como ZEIS I, que engloba as áreas informais consolidadas. Destas, 8 são loteamentos irregulares de baixa renda, 16 são consideradas favelas, 36 conjuntos habitacionais e 8 cortiços. Estes núcleos estão situados em vários bairros do município conforme Figura 1, com predominância na porção leste e oeste da cidade.

A revisão do Plano Diretor demarcou as ZEIS em Jundiaí, que até então não existiam. Esta ação indica como o município exerce seu papel de planejador do território, ao delimitar claramente os locais no território onde podem ser alocadas as habitações de interesse social. De acordo com esta proposta, as:

ZEIS I: são áreas urbanas, ainda que localizadas em áreas rurais, de ocupação consolidada, caracterizadas pela presença de assentamentos precários e irregulares, onde mora, predominantemente, população de baixa renda, em áreas públicas ou particulares, surgidos espontaneamente ou não, passíveis ou não de regularização fundiária;

ZEIS II: são compostas por áreas vazias localizadas na Macrozona de Estruturação e Qualificação Urbana, não utilizadas ou subutilizadas, adequadas à implantação de empreendimentos de Habitação de Interesse Social, em quaisquer das suas modalidades ou linhas de financiamento (JUNDIAI, 2016).

Para atuar nos assentamentos informais, a municipalidade conta com a Fundação Municipal 
de Ação Social (FUMAS), órgão responsável por atender as questões de habitação social e, em parceria com o Governo Federal, Estadual e associações de moradores, desenvolveu ações diversificadas nestes núcleos urbanos.

Este artigo apresenta os resultados de uma pesquisa que analisou intervenções realizadas no período de 2010 a 2017 nas comunidades Jardim São Camilo, Jardim Novo Horizonte, Parque Centenário e Vila Ana. São exemplos que ilustram uma atuação municipal pautada pela variedade tipológica e de soluções urbanísticas que, vistas conjuntamente, são representativas do trabalho da FUMAS.

\section{A Fundação Municipal de Assistência Social e a experiência recente de Jundiaí}

A FUMAS é a responsável pela implantação e supervisão da política habitacional: produz unidades habitacionais para as famílias inscritas em seu cadastro, efetua melhorias em bairros precários, erradicando riscos e completando a infraestrutura existente, e implanta equipamentos sociais e comunitários. Além desta atuação, a fundação também presta assistência funerária e suplementação alimentar.

A Fundação tem como diretriz "envolver a sociedade civil no desenvolvimento das atividades, visando a atuação em conjunto com as entidades representativas de moradores, além da integra- ção com o Conselho Municipal de Habitação e as parcerias com a iniciativa privada, cooperativas e convênios. " (FUNDAÇÃO MUNICIPAL DE ASSISTENCIA SOCIAL, 2018.)

A análise das ações apresentadas a seguir se restringe ao período entre 2010 a 2017, porém, como ilustra a experiência do Jardim São Camilo, a fundação vem desde 2006 atuando nos assentamentos precários em Jundiaí.

\section{Jardim São Camilo}

Localizado a leste do município e distante 2,5 km do centro de Jundiaí, o Jardim São Camilo é o caso mais complexo incluído na pesquisa. $\mathrm{O}$ bairro apresenta uma topografia acentuada, que, segundo Pereira (2016), atinge em média de $20 \%$ a $30 \%$ de inclinação. Com isso, a caracterização geomorfológica da ocupação é de encosta de morro e, devido à alta declividade, apresenta problemas de instabilidade geotécnica em algumas regiões.

A ocupação irregular teve início nas décadas de 1940 a 1960, conforme levantamento realizado pela FUMAS, acontecendo em uma área particular e parte no sistema de lazer do loteamento de mesmo nome. Dados cadastrais da FUMAS mostram que a quantidade de imóveis levantados em 2015 no assentamento precário é de 1.618 - contando com 4.879 habitantes - em área aproximada de 14,40 hectares, com densidade habitacio- 


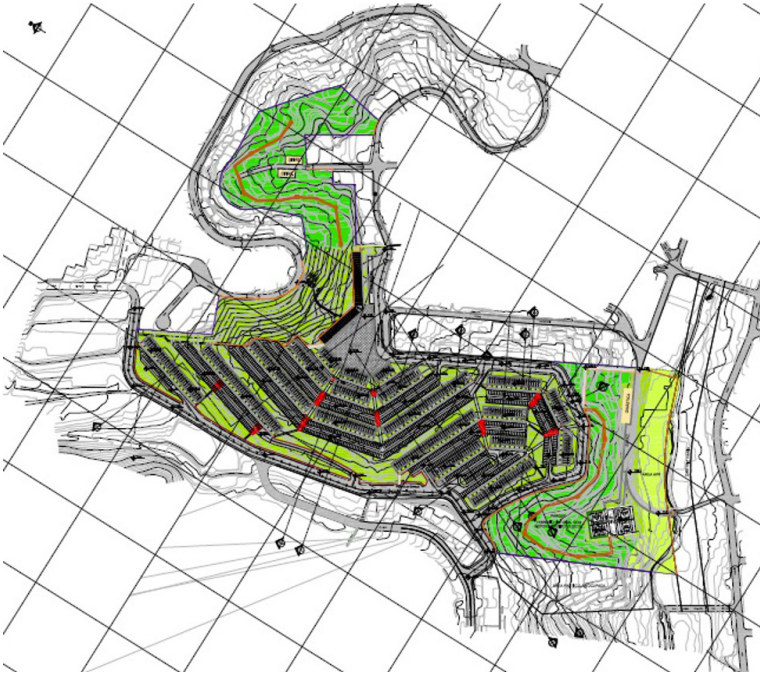

Figura 2. Implantação do primeiro projeto de remanejamento (relocação) do Jardim São Camilo, que comtemplava a remoção total dos moradores do assentamento. Fonte: Implantação produzida pela FUMAS.

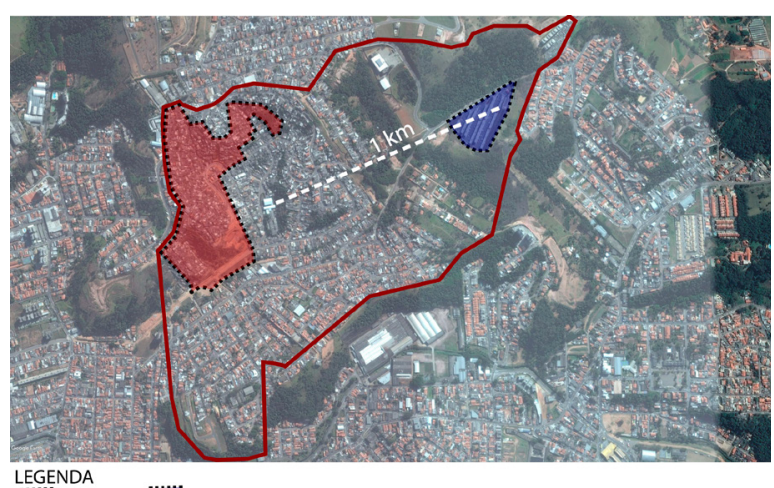

LEGENDA

Figura 3. Demonstra a distância do local escolhido para reassentamento em relação ao núcleo original, ago 2016. Fonte: Elaborado por por Sarah Monteferrante a partir de imagem do Google Maps, 2016.

usjt • arq.urb • número 24 | janeiro - abril de 2019 nal bruta de 338,81 hab/ha, aproximadamente. A configuração do assentamento é de um traçado desordenado, cujos acessos aos moradores são realizados por escadarias ou vielas estreitas. Quase não existe acesso para veículos, o que dificulta a ligação do núcleo com o bairro.

Desde 2006, foram efetuadas ações pontuais como: a doação de materiais para reforma de casas; a remoção (2006) de três famílias que se encontravam em áreas de risco para um conjunto habitacional a construção (2008) de uma escadaria hidráulica na viela do Lixão, com remoção de 40 famílias para o residencial Morada das Vinhas, da CDHU, a aproximadamente 6 quilômetros do Jardim São Camilo.

Em 2008, a Fundação contratou um Plano Urbanístico, desenvolvido pelo arquiteto Paulo Bastos, para a Viela do Pelé, buscando melhorar as condições de moradias das familias lá residentes. Este contaria com algumas remoções e a realocação na mesma área de prédios de apartamentos que aproveitariam a declividade do local sem promover grande movimentação de terra. No entanto, o projeto foi abandonado e, segundo relato dos técnicos, o motivo foi a dificuldade de remoção do entulho que a obra produziria.

Em 2011, a prefeitura de Jundiaí aprovou um projeto de urbanização junto ao Ministério das Cidades, vinculado ao PAC (PAC II/ PPI Favelas - Infraestrutura - Urbanização de Assentamen- tos Precários), para toda a área de ocupação do Jardim São Camilo (PEREIRA, 2015). Este projeto previa a remoção total das famílias e a construção de apartamentos na mesma área desocupada. Porém, não contemplava a construção de moradias para todas as famílias, sobrando um remanescente de aproximadamente 700 famílias, para as quais seria necessário o reassentamento em área próxima. De acordo com Pereira (2015, p. 305), a intervenção acarretaria a "[...] demolição de casas consolidadas dotadas de infraestrutura como abastecimento de água, esgoto e boas condições de habitabilidade". Para este projeto foi prevista a construção de 1.260 unidades pelo PMCMV (PEREIRA, 2015) no mesmo sítio do assentamento original, com implantação seguindo o desnível do terreno, usando um tipo de edificação residencial que acomodava as unidades em platôs reconstruídos sobre o desnível natural (Figura 2).

Contudo, a FUMAS e a Prefeitura não dispunham de local para reassentamentos das famílias remanescentes, tendo apenas uma área localizada, aproximadamente, a 1 quilometro no núcleo irregular (Figura 3), que atenderia apenas 400 unidades habitacionais, tornando assim inviável a intervenção (PEREIRA, 2015) (Figura 3). Outro ponto que inviabilizou a intervenção foi a falta de participação e legitimação da comunidade envolvida, que não foi, em momento algum, comunicada sobre o mesmo. 


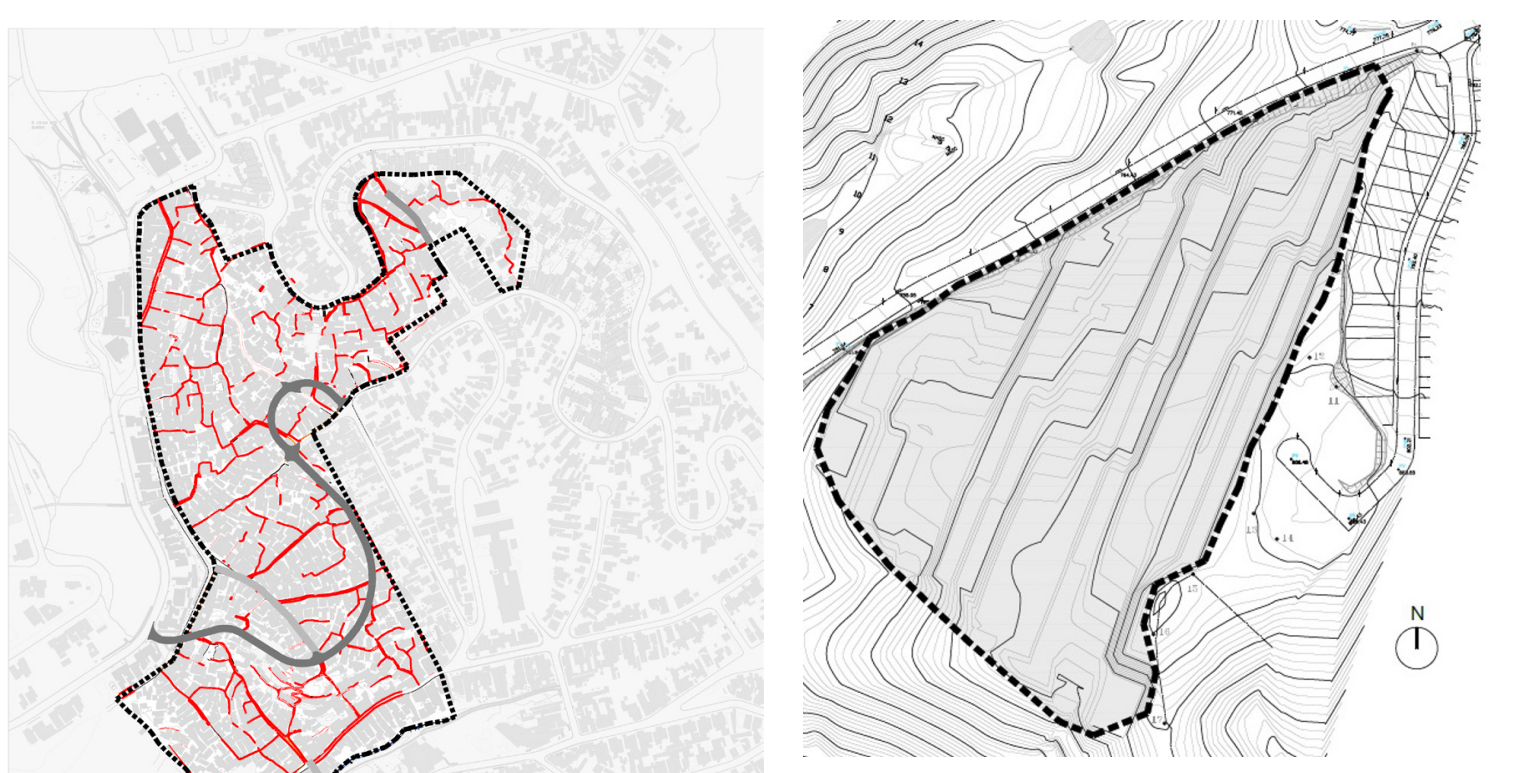

Figura 5: Levantamento planialtimétrico da área de reassentamento. Realizado pela TS engenharia em nov. 2010. Fonte: FUMAS.

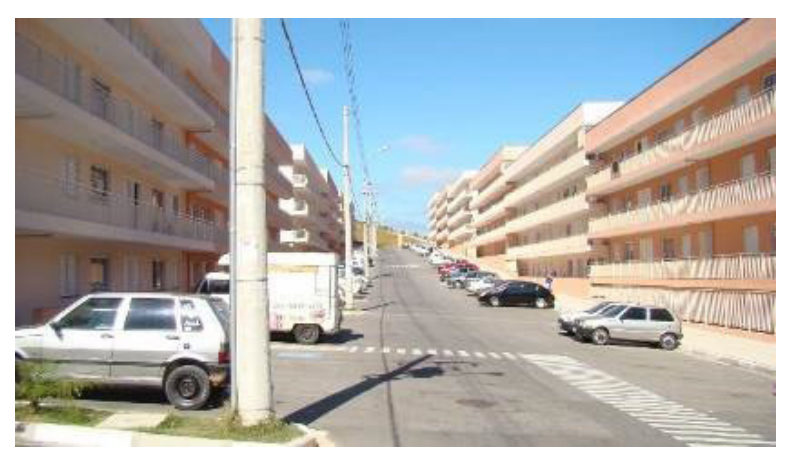

Figura 6: Residencial Gênova, área do reassentamento, ago. 2016. Fonte: Arquivo das autoras.
Outro estudo foi elaborado e, em maio de 2014, foram iniciadas as obras sob objeto do contrato de repasse PT n 03.52.654-44/2011, que trata do convênio entre o Ministério das Cidades, a Caixa Econômica Federal (CAIXA) e a Prefeitura de Jundiaí/FUMAS, com recursos do PAC e do PMCMV (JUNDIAÍ, 2015).

Este projeto prevê a implantação de uma nova via (Figura 4) que fará a interligação da parte alta (norte) com a parte baixa (sul) do bairro, melhorando a mobilidade e o acesso ao centro. Também a implantação do sistema de drenagem e o aumento vazão da tubulação de esgoto.

A implantação removeu famílias que foram realojadas em 400 unidades habitacionais no terreno da Figura 3. A obra recebeu recursos dos Governos Federal e Estadual, totalizando $\mathrm{R} \$ 38,40$ milhões pelo PMCMV - Faixa 1 - FAR (Fundo de Arrendamento Residencial) (PEREIRA, 2015). O estudo preliminar foi elaborado pela FUMAS e as adequações para obra executadas pela empresa Faleiros, contemplada pelo chamamento (PEREIRA, 2015). O terreno para a implantação das unidades também apresenta acentuada declividade, conforme Figura 5. A Figura 6 ilustra a implantação das unidades habitacionais.

Foram realizadas as construções de dois conjuntos habitacionais denominados Gênova e Roma. As unidades habitacionais compreendem sala, cozinha, área de serviço, dois dormitórios, com área útil de $45,39 \mathrm{~m}^{2}$ e acesso em galeria, sem elevador. Cada apartamento recebeu também uma vaga para veí- 
culos e os edifícios possuem quatro pisos (térreo e mais três andares), situados em grandes platôs que exigiram considerável movimentação de terra.

As famílias beneficiadas com as unidades habitacionais de forma não onerosa, ou seja, não pagam financiamento e os imóveis foram doados com a isenção do Imposto de Transmissão Causa Morte de Doação (ITCMD). Pagam o condomínio e estiveram isentas do pagamento do Imposto Predial e Territorial Urbano (IPTU) até o final de 2017 (a partir daí já iniciaram o pagamento).

\section{Jardim Novo Horizonte}

Localizado no vetor oeste do município e a uma distância de aproximadamente 9,5 km das áreas centrais de Jundiaí, o Jardim Novo Horizonte, antigo Varjão, possui uma extensão de 7 km sobre o antigo leito de um ramal da Estrada de Ferro Sorocabana (Figura 7) com largura média de 60 metros (PEREIRA, 2016). A principal via do bairro é a Estrada Municipal do Varjão, ligando-o ao município de Itupeva. A topografia é predominantemente plana.

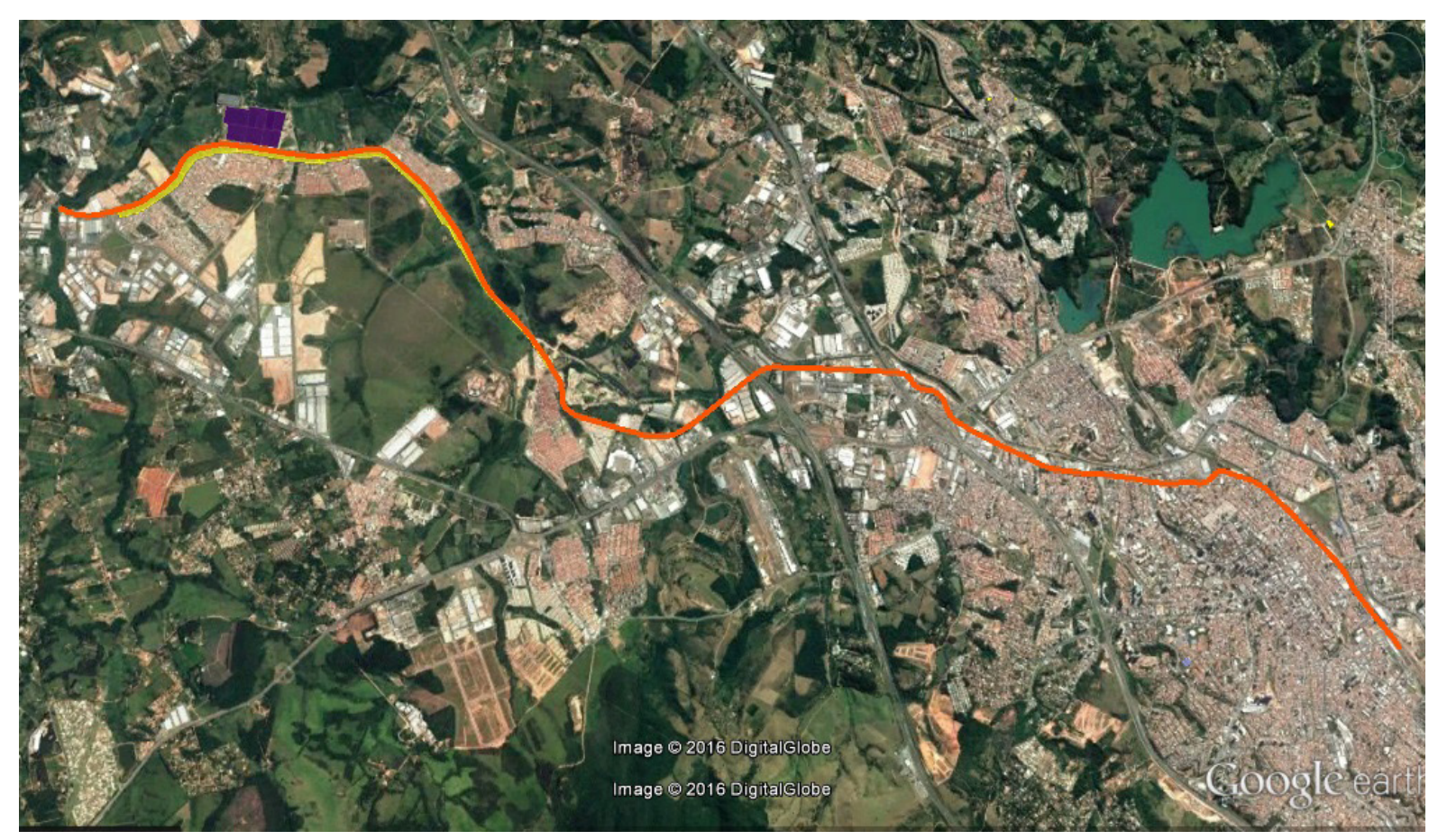

Figura 7. Área do assentamento precário Jardim Novo Horizonte, antigo Varjão. Em laranja a demarcação do antigo leito da estrada de ferro Sorocabana. Fonte: Elaborado pelas autoras sobre imagem aérea do Google maps. 


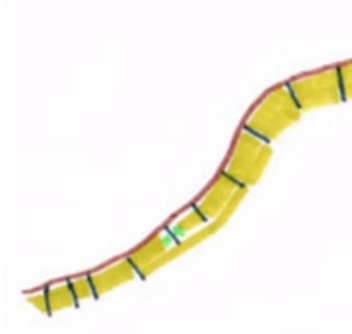

DPETALHE

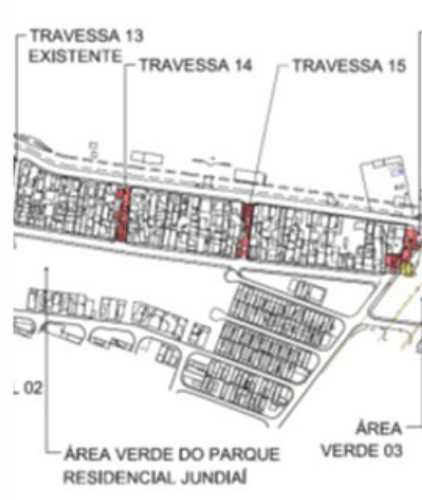

LNHA DE TRAMISSÁ
DE ENERGIA ELÉTRICA

TRAVESSA 16

TRAVESSA 17

TRAVESSA 18

the thensuissä
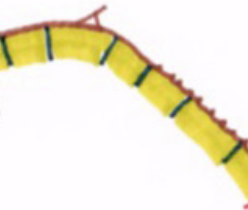

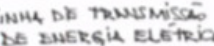

Figura 8. Croqui da implantação demosntrando as propostas das aberturas das vias e detalhes das possíveis remoções. Fonte: Implantação produzida pela FUMAS. Adaptado pelas autoras.
A ocupação do Jardim Novo Horizonte iniciou-se após o processo de falência da Ferrovia Paulista S.A. - Fepasa, trecho da antiga Sorocabana (OLIVEIRA, 2014) pelos trabalhadores da própria ferrovia, por trabalhadores de fazendas desativadas e pela marcha da industrialização, impulsionando a migração de população por todas as regiões do país à São Paulo (OLIVEIRA, 2014).

Dados cadastrais da FUMAS, 2015, mostram que na ocupação estão presentes 8.891 pessoas, sendo
3.205 famílias e 3.112 imóveis registrados. A densidade aproximada é de 211,69 hab/ha. Suas edificações são mistas, não ultrapassando dois pavimentos, em alvenaria e poucas de madeira.

Em 2008 a prefeitura doou à CDHU uma área próxima ao núcleo do Novo Horizonte que previa a construção de 581 unidades habitacionais, denominada de "Jundiaí L". Este empreendimento atenderia à "faixa 1", população com renda familiar de um a três salários mínimos. No entanto, este projeto não logrou êxito e o terreno foi devolvido para a Prefeitura de Jundiaí.

Em agosto de 2013, a prefeitura recebeu recursos do Ministério das Cidades para o início da execução do projeto de urbanização do Jardim Novo Horizonte (PEREIRA, 2015). Este projeto, desenvolvido pelo escritório Projeto Paulista, visava melhorar a mobilidade e acessibilidade dos moradores, ao criar 35 vias transversais ao núcleo, interligando os bairros sem que os moradores percorram toda extensão (Figura 8). Foram propostas vias e respectivas quadras, bem como a desocupação de moradias em faixas de APP, nas margens do córrego e moradias na área não edificante, sob a rede de alta tensão. Com isso seria necessário à remoção de 544 famílias que estariam no local da abertura das ruas. A FUMAS relatou que, ao final, todas as famílias mantidas no assentamento original terão a posse dos imóveis, sendo a regularização fundiária o objetivo final da intervenção que ainda está em andamento. 


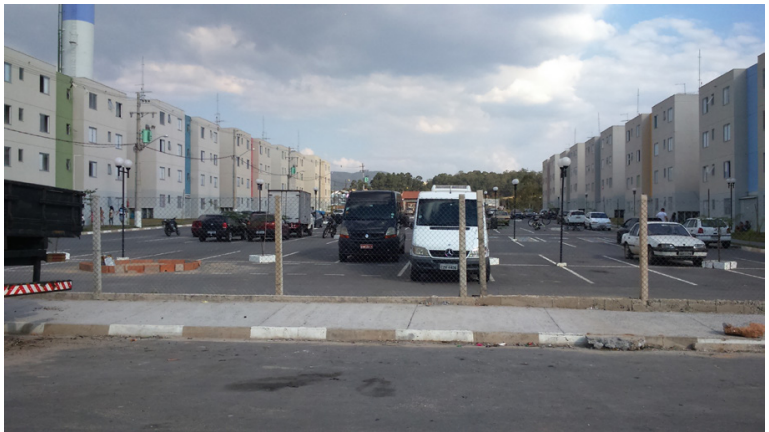

Figura 9. Condomínio Residencial Jardim Novo Horizonte ago. 2016. Fonte: Arquivo pessoal.
Em 2014 a prefeitura iniciou as obras de um empreendimento próximo ao núcleo com 1088 apartamentos pelo Programa Minha Casa Minha Vida Faixa 1 - FAR para atender à demanda geral do município, além de uma escola, uma creche e um viaduto. Ao final, o empreendimento terá ainda áreas comerciais e um parque para esporte e lazer. (PEREIRA, 2016, p.321).

[...] empreendimento compreendendo 1.088 unidades habitacionais (apartamentos), localizados próximo à área de assentamento, 2 unidades escolares (escola, creche) pelo Programa Minha Casa Minha Vida (PMCMV) Faixa 1 - FAR além de um viaduto, áreas comerciais que serão licitadas e parque para esporte e lazer (PEREIRA, 2016, p.321).

Para o Novo Horizonte foram previstas 544 unidades deste empreendimento, para atender as famílias que seriam removidas quando das aberturas das vias. Porém, até o ano de 2017 foram executadas apenas quatro vias acarretando a remoção de aproximadamente 170 famílias. Assim, as demais unidades habitacionais foram destinadas à demanda difusa do município.

Para tanto, foram produzidas 64 torres de apartamentos, com quatro apartamentos por andar e quatro andares em cada torre, separadas por condomínios - cada um apresentando, em média, 12 blocos. Ao todo, são seis condomínios. Figura 9 mostra um conjunto de apartamentos.
A unidade habitacional possui 45,09 m², compreendendo sala, cozinha, área de serviço, dois dormitórios, uma vaga de veículo. $\mathrm{O}$ edifício tem planta em "H", com térreo e mais três pavimentos, apresentando área para futuro elevador (Figura 8). Para a construção destes apartamentos o município contou com verbas do Programa Minha Casa Minha Vida e do Programa Casa Paulista do Governo Estadual. O projeto foi desenvolvido pela construtora Engelux em parceria com o escritório Ilha Arquitetura. As famílias beneficiadas com as unidades habitacionais pagam os valores referentes ao estipulado pelo PMCMV, entre 25 e 80 reais por mês, durante dez anos, mais a taxa condominial. O restante foi subsidiado pelo Governo Federal.

\section{Parque Centenário (Jardim Nascente)}

O assentamento Parque Centenário está localizado a norte do município de Jundiaí a 6 quilômetros da região central. A ocupação teve início em 1980 na área de sistema de lazer do loteamento e em parte na área de APP (Figura 10). Apresenta topografia bem acentuada, uma ocupação desordenada com moradias em condições de insalubridade e algumas em risco ou implantadas em área de preservação permanente.

Segundo levantamento da FUMAS realizado nos meses de maio a junho de 2016, 128 famílias foram cadastradas num total aproximado de 512 pessoas em área aproximada de 29.078,33 m², com densidade bruta de 176,55 hab/ha. 


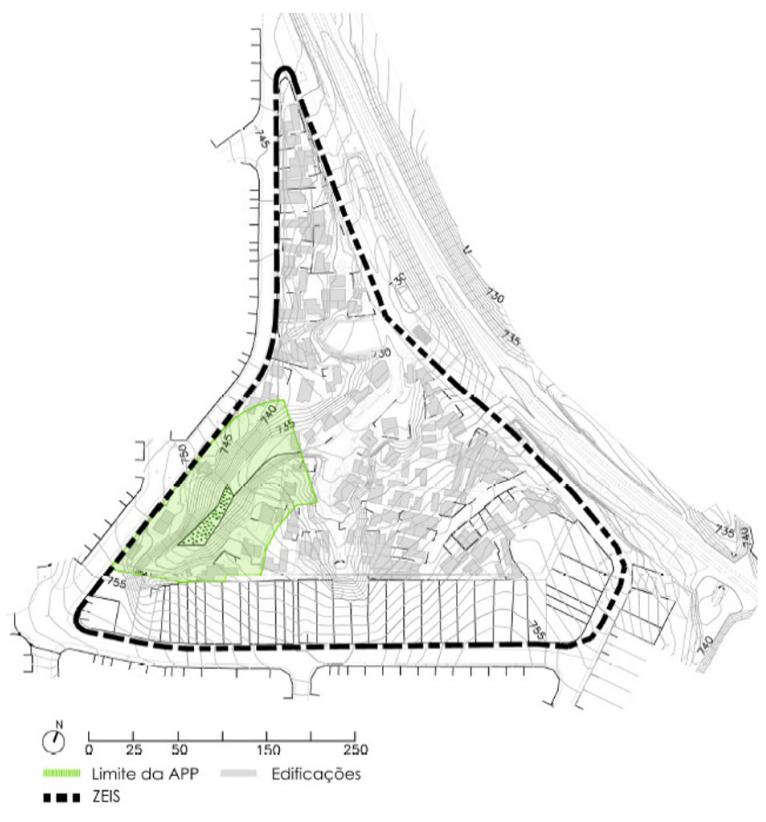

Figura 10. Levantamento planialtimétrico cadastral do Parque Centenário mostrando a declividade na área de APP e a presença de moradias, confrontando com lotes regulares ao sul. Fonte: Elaborado pelas autoras a partir de levantamento cedido pela FUMAS.

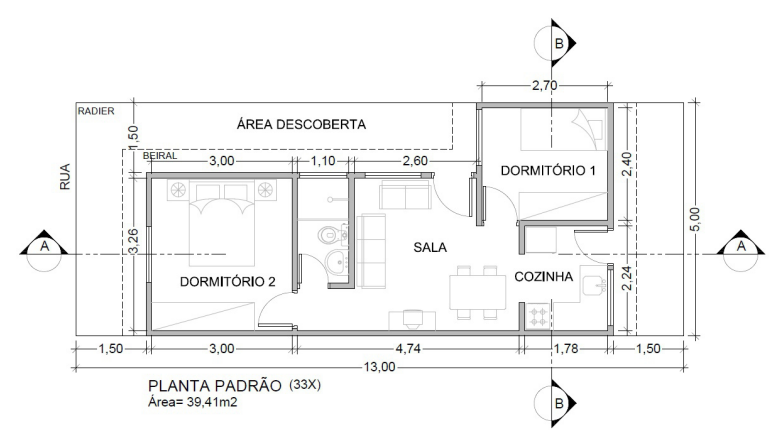

Figura 11. Planta do projeto embrião das novas casas do Jardim Nascente, desenvolvidas pelos técnicos da FUMAS. Fonte: Acervo da FUMAS.

usjt • arq.urb • número 24 | janeiro - abril de 2019
O projeto de urbanização realizado no Parque Centenário, que teve seu nome mudado para Jardim Nascente para não coincidir com o loteamento de mesmo nome, contou com a remoção das famílias presentes nas áreas de risco e a abertura de novas ruas, tornando possível a interligação entre elas, a remoção e construção de novas moradias e a meIhora na infraestrutura, com redes de água, esgoto e eletricidade.

Foram construídas trinta e três novas moradias, com um projeto denominado edificação evolutiva (Figura 11) e 78 casas receberam material e mão-de-obra da FUMAS, através de doação, para reformas. Ao todo 111 famílias foram beneficiadas.

De acordo com a FUMAS, as famílias que receberam as casas ainda não estão pagando por elas, pois não foi definido se devem, ou não, pagar o Termo de Permissão de Uso (TPU). O processo de regularização fundiária ainda está em curso.

\section{Vila Ana}

Situado a oeste do município e próximo a uma das vias mais importantes de Jundiaí a avenida Nove de Julho, o assentamento está localizado a $2 \mathrm{~km}$ do centro. Teve origem na década de 1960, e sua ocupação ocorreu principalmente em áreas públicas e se estendeu, em grande parte, aos lotes particulares adjacentes, uma praça e algumas vias. A situação original era de moradias precárias, a grande maioria das construções eram barracos de madeira (Figura
12) e a Figura 13 ilustra os lotes que eram originalmente ocupados por barracos antes da intervenção. No total, a ocupação tem área de 0,669 hectares e uma densidade de $860,98 \mathrm{hab} / \mathrm{ha}$. Segundo dados cadastrais da FUMAS 2007, constatou a existência de 155 moradias, residindo 622 pessoas.

Desde a década de 1990, foram realizadas intervenções no assentamento buscando a melhoria na qualidade de vida da população. A primeira implantou 16 unidades habitacionais, sendo 11 construídas pela FUMAS e cinco pela paróquia do bairro. Ainda neste período, e através do sistema de mutirão, foram construídas 70 unidades habitacionais em área denominada Jardim Anhanguera. Porém ainda faltavam melhorar as condições de aproximadamente 161 famílias. Assim foram ofertadas 17 unidades habitacionais para famílias que gostariam de se mudar para um conjunto habitacional em um outro bairro denominado Cidade Jardim II. Esta oferta de mudança de bairro se deu devido ao fato da não possibilidade de acomodar todas as famílias no mesmo bairro.

Foi realizado um planejamento específico para acomodar as famílias durante as obras, abrindo frentes de obra parciais e relocando paulatinamente a população. A construção das 144 unidades habitacionais foi dividida em três etapas e para a realização destas foi necessário a construção de alojamentos provisórios, dentro do próprio bairro, evitando, assim, impactos na rotina das pessoas. 


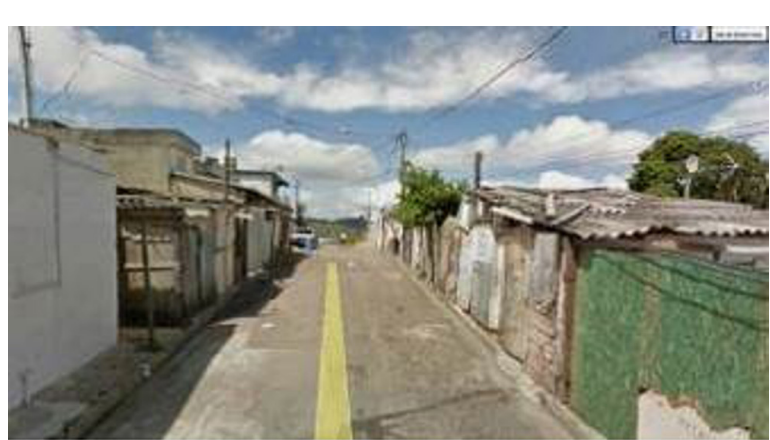

Figura 12: Foto mostrando a ocupação da Vila Ana antes da intervenção, 2006. Fonte: Imagem do Google Earth, 2006. Acesso em: 12 nov. 2017

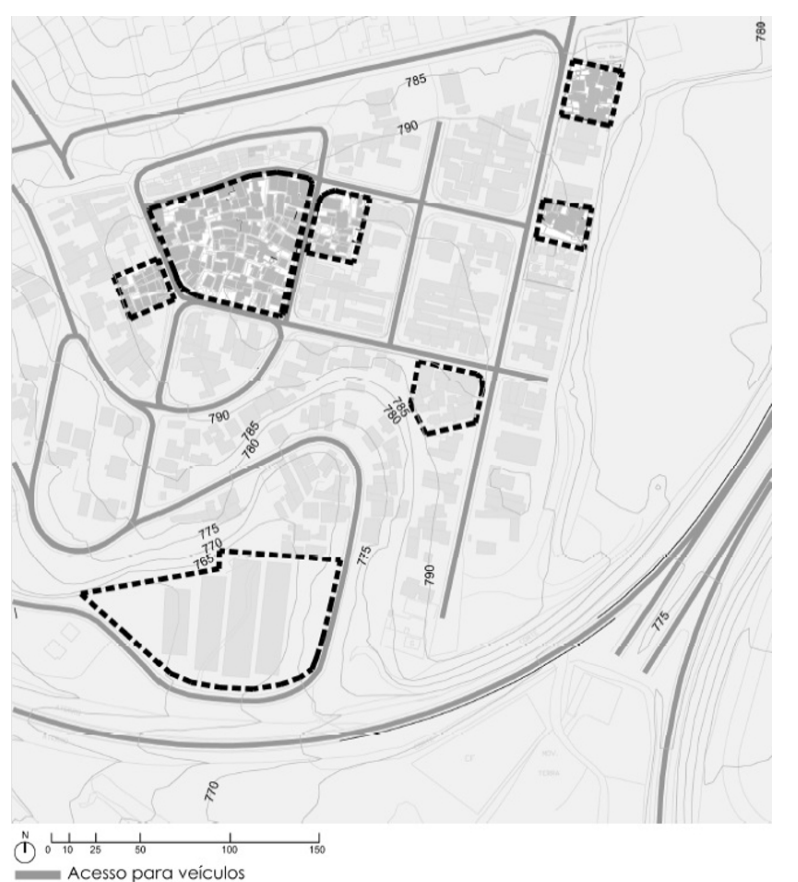

Acesso para veiculos

-1. Limite ZE IS

Figura 13: Foto mostrando lotes ocupados antes da intervenção. Fonte: Mapa produzido a partir do levantamneto Cdastral da Secretaria de Planejamento e Meio Ambiente de Jundiaí e da FUMAS. Elaborado pelas autoras.

usjt • arq.urb • número 24 | janeiro - abril de 2019

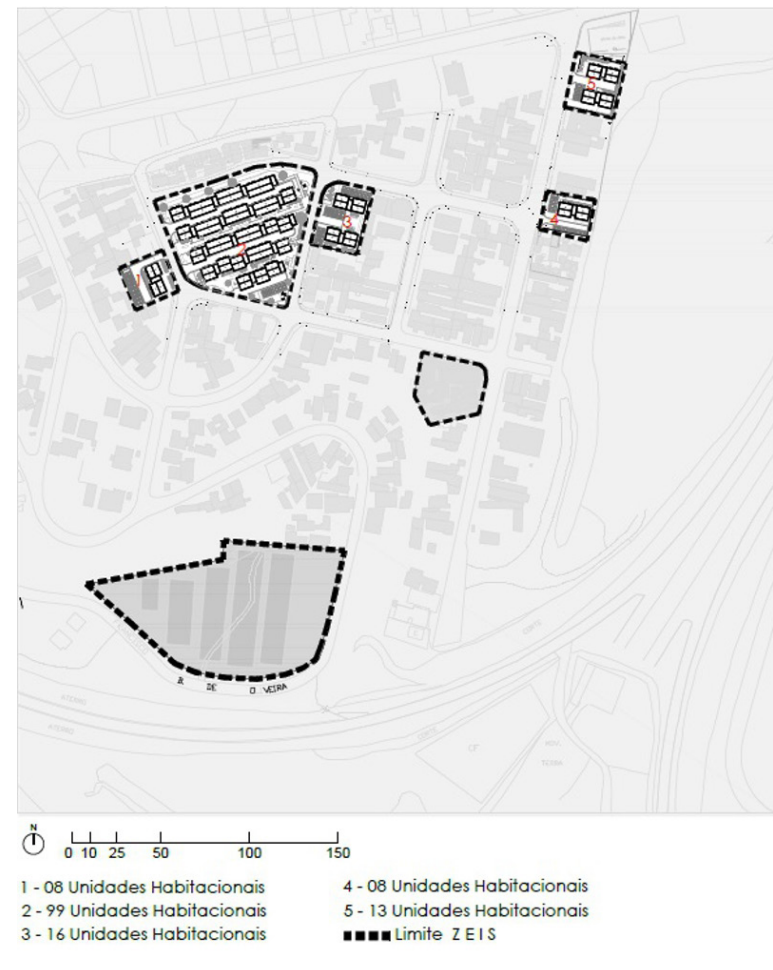

Figura 14: Implantação a unidade habitacionais. Projeto do arquiteto Pier Paolo B. Pizzolato. Fonte: Arquivo da FUMAS, elaborado pelas autoras.

A primeira etapa foi entregue em 2011, com 36 unidades habitacionais (de um total de 99), fazendo parte do conjunto 02. A segunda etapa contou com entregas em anos diferentes: conjunto 01 , composto de 8 unidades em um terreno de $600 \mathrm{~m}^{2}$, entregue em agosto de 2015; conjunto 02, mais 63 unidades, também em agosto de 2015, completando as 99 unidades previstas, com área de terreno de 4.467,94 $\mathrm{m}^{2}$. O conjunto 03 , com 16 unidades habitacionais em terreno de $900 \mathrm{~m}^{2}$, foi entregue em novembro de
2016; o conjunto 04, com oito unidades em terreno com área de $550 \mathrm{~m}^{2}$, em abril de 2017. Por fim, o bloco 05, com 13 unidades em área de $775,49 \mathrm{~m}^{2}$, entregue também em abril de 2017 , totalizando assim cinco áreas de intervenção, com 144 obras de urbanização (Figura 14).

Os tipos habitacionais implantados possuem área de $54 \mathrm{~m}^{2}$ cada. Os apartamentos foram feitos sobre pilotis para abrigarem as garagens de automóveis no pavimento térreo. Estas obras obtiveram verbas do Ministério das Cidades, através da CAIXA, e contrapartida da PMJ/FUMAS.

As famílias contempladas com as unidades habitacionais pagam a Taxa de Permissão de Uso (TPU) referente a $10 \%$ da renda familiar, limitada a um valor de prestação aproximado de $\mathrm{R} \$ 158,00 \mathrm{em} \mathrm{dez}$ anos. Com relação à taxa de manutenção das áreas comuns, os valores variam entre os conjuntos. Onde há mais unidades, a taxa é menor - $R \$ 60,00-$, pois existem mais moradores para dividir os custos. Nos conjuntos onde há menos unidades, a taxa varia entre $R \$ 70,00$ e $R \$ 100,00$ reais, pois existem menos moradores para ratear os custos de manutenção. Estas informações foram transmitidas pela FUMAS.

\section{Síntese das ações de urbanização de favelas:} diversidade locacional, tipológica e de soluções

As ocupações ora apresentadas surgiram a partir das décadas de 1960, 70 e 80, e estão implantadas em terrenos com situações fundiárias distintas entre 
áreas públicas e privadas. As públicas são espaços livres de loteamento e leitos viários enquanto que as áreas privadas variam de lotes particulares ao antigo leito ferroviário, hoje uma área pública. Os núcleos apresentam diversidade na topografia: áreas de grande declividade, como é o caso do São Camilo e Parque Centenário, e outros, com pouca ou nenhuma declividade como Vila Ana e Jardim Novo Horizonte, respectivamente. Por fim, há diferentes graus de precariedade do espaço habitado, manifestado pelas distintas taxas de densidade na ocupação original (sendo 176,55 a densidade mínima verificada no Parque Centenário / Jardim Nascente e 860,98 a taxa máxima, calculada na Vila Ana) e qualidade das edificações, permitindo, em alguns casos, a manutenção das moradias produzidas pelos moradores.

Esta diversidade de ocupação e localização refletem na maneira em que foram realizadas as urbanizações, exigindo ou não áreas externas para acomodar a população removida. Enquanto no Jardim São Camilo e Novo Horizonte os moradores removidos foram realocados em área próxima ao assentamento original, o Jardim Nascente e Vila Ana mantiveram os moradores no próprio local, ainda que reconstruído total ou parcialmente.

Considerando a classificação usada por Denaldi (2009), todas as áreas são consideradas "consolidáveis", para as quais se recomenda urbanização complexa ou simples. São Camilo e Novo Horizonte eram áreas consolidáveis de urbanização complexa, pois dependem de alto índice de remoção para im- plantação de redes de infraestrutura urbana e novo desenho urbano, demandando também áreas externas para acomodar as famílias removidas. Vila Ana também é um caso considerado de urbanização complexa, cuja altíssima densidade e situação em um bairro consolidado, de renda média, levaram à escolha de remoção total com posterior reocupação dos terrenos com edifícios, mantendo a densidade populacional da ocupação prévia. Já o Parque Centenário é uma área de urbanização simples, permitindo as readequações da infraestrutura urbana e a eliminação da precariedade habitacional sem remoção externa.

Outro aspecto importante de ser mencionado é que toda a regularização urbanística teve como objetivo realizar a regularização fundiária das quatro comunidades, que depende, contudo, da conclusão das obras. A Figura 15 a seguir sintetiza as intervenções:

Com relação aos tipos habitacionais implantados, as soluções não foram padronizadas e as escolhas arquitetônicas foram definidas pelo contexto no qual se desenvolveu cada projeto. A síntese dos empreendimentos pode ser vista na Figura 16.

O projeto desenvolvido por Paulo Bastos para o Jardim São Camilo tinha por partido respeitar as características físicas locais do terreno e se adaptar a ele, a partir da adoção de um tipo arquitetônico para encostas. $\mathrm{O}$ argumento de que o projeto era inviável por conta da dificuldade da remoção do entulho considera que este só pode ser conduzido por gran- 


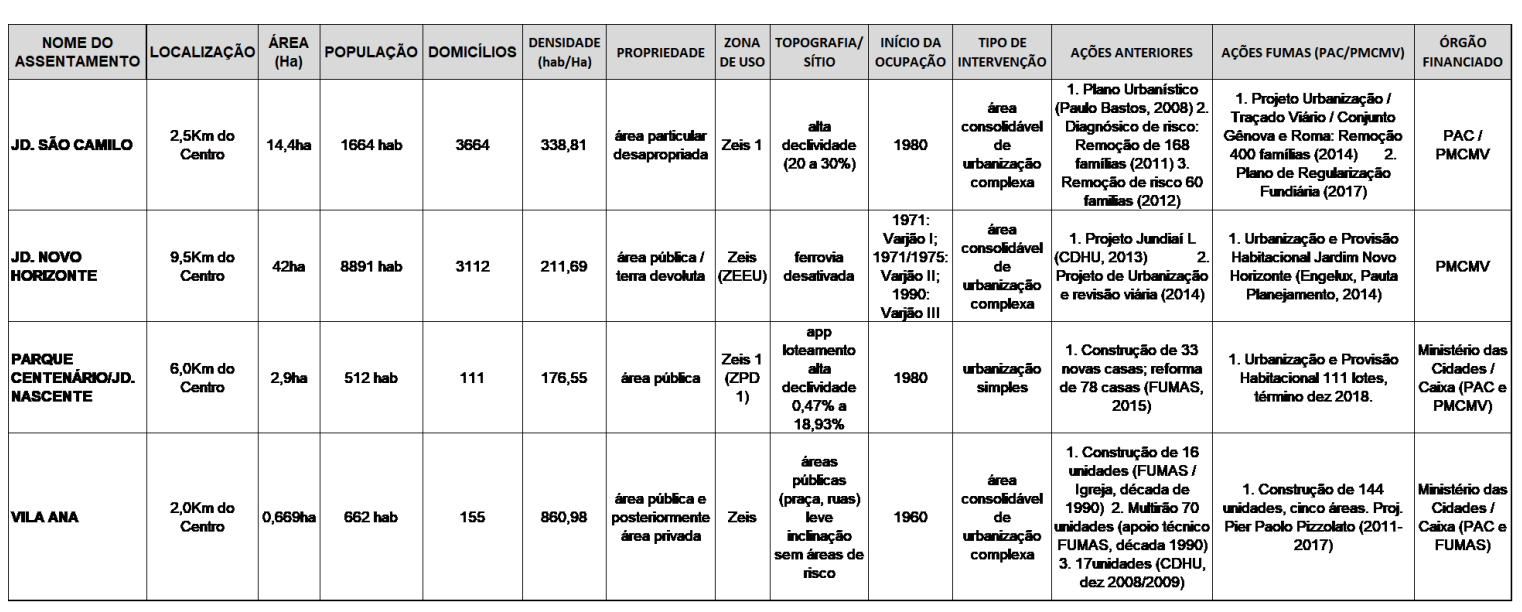

Figura 15. Síntese das intervenções realizadas nos núcleos Jardim São Camilo, Jardim Novo Horizonte, Parque Centenário e Vila Ana. Fonte: Elaborado pelas autoras.

\begin{tabular}{|c|c|c|c|c|c|c|c|c|}
\hline $\begin{array}{c}\text { NOME DO } \\
\text { ASSENTAMENTO }\end{array}$ & \begin{tabular}{|c} 
ABRANGÊNCIA \\
DE \\
ATENDIMENTO
\end{tabular} & \begin{tabular}{|c|} 
DESTINO \\
DAS \\
FAMÍLIAS \\
REMOVIDAS \\
\end{tabular} & $\begin{array}{c}\text { CUMPRIMENTO } \\
\text { DOS } \\
\text { PROJETOS }\end{array}$ & $\begin{array}{c}\text { TIPOLOGIA } \\
\text { ARQUITETÓNICA }\end{array}$ & $\begin{array}{c}\text { CRITÉRIOS PARA } \\
\text { REMOÇÃo }\end{array}$ & $\begin{array}{l}\text { INFRAESTRUTURA } \\
\text { URBANA DO } \\
\text { ASSENTAMENTO E } \\
\text { ENTORNO } \\
\end{array}$ & $\begin{array}{l}\text { PROCESSOS } \\
\text { DE OBRA }\end{array}$ & $\begin{array}{l}\text { SITUACCÃo } \\
\text { FUNDIÁRIA }\end{array}$ \\
\hline JD. SÃO CAMILO & $\begin{array}{l}400 \text { faminas } \\
\text { atendidas }\end{array}$ & \begin{tabular}{|c|} 
Residencial \\
Gênova e Roma
\end{tabular} & atendido & edificios em lamina & $\begin{array}{c}\text { moradores ao } \\
\text { longo da área da } \\
\text { abertura da via }\end{array}$ & $\begin{array}{l}\text { infraestrutura básica } \\
\text { porém incompleta }\end{array}$ & $\begin{array}{c}\text { sem } \\
\text { alojamento }\end{array}$ & $\begin{array}{c}\text { pequena porção } \\
\text { regularizada }\end{array}$ \\
\hline $\begin{array}{l}\text { JD. NOVO } \\
\text { HORIZONTE }\end{array}$ & $\begin{array}{c}170 \text { fammias } \\
\text { atendidas }\end{array}$ & $\begin{array}{c}\text { Conjunto } \\
\text { Habitacional }\end{array}$ & parcial & edificios $\mathrm{em} \mathrm{H}$ & $\begin{array}{l}\text { moradores ao } \\
\text { ongo da área da } \\
\text { abertura da via }\end{array}$ & $\begin{array}{l}\text { infraestrutura básica } \\
\text { porém incompleta }\end{array}$ & $\begin{array}{c}\text { sem } \\
\text { alojamento }\end{array}$ & $\begin{array}{c}\text { em fase de } \\
\text { kevantamento de } \\
\text { uma pequena } \\
\text { porção }\end{array}$ \\
\hline $\begin{array}{c}\text { PARQUE } \\
\text { CENTENÁRIO/JD. } \\
\text { NASCENIE }\end{array}$ & $\begin{array}{l}111 \text { familas } \\
\text { atendidas }\end{array}$ & $\begin{array}{c}\text { mesmo local do } \\
\text { assentamento }\end{array}$ & atendido & $\begin{array}{c}\text { construção de } \\
\text { novas casase } \\
\text { reformas }\end{array}$ & $\begin{array}{l}\text { não houve } \\
\text { remoção }\end{array}$ & $\begin{array}{l}\text { infraestrutura básica } \\
\text { porém incompleta }\end{array}$ & $\begin{array}{c}\text { deslocamentos } \\
\text { temporários }\end{array}$ & $\begin{array}{l}\text { em trâmites } \\
\text { cartorários }\end{array}$ \\
\hline VLA ANA & $\begin{array}{c}144 \text { famitas } \\
\text { atendidas - útima } \\
\text { fase }\end{array}$ & $\begin{array}{c}\text { mesmo local do } \\
\text { assentamento }\end{array}$ & atendido & edificios sob platis & $\begin{array}{l}\text { não houve } \\
\text { remoção }\end{array}$ & $\begin{array}{l}\text { infraestrutura básica } \\
\text { porém incompleta }\end{array}$ & $\begin{array}{l}\text { alojamento } \\
\text { provisório }\end{array}$ & $\begin{array}{l}\text { irregular, porém } \\
\text { IEPAC já rearzado }\end{array}$ \\
\hline
\end{tabular}

Figura 16. Soluções para o reassentamento das famílias removidas nos empreendimentos analisados. Fonte: Elaborado pelas autoras. des equipamentos, o que não é verdade. É, contudo, uma intervenção mais delicada, característica dos projetos de urbanização da década de 1990 verificados em vários exemplos brasileiros, com tipos que se misturam à paisagem pré-existente, compondo com ela. Este projeto foi substituído por outro (Figura 2), bastante agressivo, que remove a totalidade das moradias e realiza uma considerável movimentação de terra, em nome da implantação de edifícios padronizados e desenhados para áreas planas.

Felizmente foi abandonado, uma vez que certamente a prefeitura não teria recursos para implantá-lo integralmente e apenas parte da população teria o destino do conjunto habitacional na área de reassentamento da Figura 3, ficando as demais sem alternativa. Por fim, a solução urbanística encontrada partiu do número de 400 unidades habitacionais definidas pela proposta para área de reassentamento (Figura 5), os empreendimentos Gênova e Roma. Aqui, também, o tipo habitacional não considera a encosta do terreno ao qual se destina, realizando grande movimentação de terra para implantação de dois edifícios em lâmina conectados por uma via larga, ladeada por vagas de estacionamento. Outro desenho conseguiria implantar um número maior de unidades, em situações de escalonamento e acessadas por vias de meia encosta, por exemplo, que consomem menos espaço e exigem menor recurso em terraplanagem. Assim, fixou-se em 400 o número de edificações que poderia ser removido do sítio original, levando à adoção de um desenho viário limitado às possibilidades de atendimento às famílias. 
O Novo Horizonte é exemplar de uma situação comum em vários municípios, semelhante também ao São Camilo, de que o desenvolvimento da obra de urbanização está sujeito às possibilidades de acomodação das famílias removidas. Tão logo ficam prontas as unidades habitacionais previstas em uma área externa - no caso, um empreendimento do Minha Casa Minha Vida para atender ao déficit habitacional do município - as frentes de obra vão avançando. Porém, a prefeitura paralisou as obras de urbanização mesmo tendo as unidades habitacionais prontas, que foram ocupadas por outra população que não a da área inicialmente planejada. Do ponto de vista da qualidade da habitação, o empreendimento não difere em nada dos inúmeros conjuntos habitacionais financiados pelo programa federal, com arquitetura conservadora e monótona.

A Vila Ana é também um caso complexo, em que a solução de resolver lote a lote foi adequada, evitando a abertura de frente de obras simultâneas que desalojassem, de uma vez, todas as famílias. As cinco fases do projeto foram recebendo paulatinamente os moradores removidos e o tempo em alojamento provisório foi curto, ainda que, como relatado pelas famílias, bastante desconfortável. Dos quatro visitados, esta foi a urbanização em que a população mais se envolveu nas decisões projetuais e das obras, reconhecendo o esforço dos técnicos locais em diminuir o desgaste. $\mathrm{O}$ tipo habitacional de torre sobre pilotis foi definido especialmente para o local, inserindo-se de forma adequada à paisagem e aprovado pelos moradores. A participação popular e o desenho das edificações contribuíram para a aprovação dos beneficiados verificada na visita técnica.

Finalmente, o Jardim Nascente é uma intervenção que redefine os lotes onde houve remoção de moradias, construindo unidades evolutivas (embriões) que são concluídas pelos moradores. A maior parte dos lotes preexistentes foi consolidada, com assistência técnica às famílias que receberam materiais de construção para reformas. As remoções se deveram às situações de risco, moradias muito precárias, às quais não se recomenda sua consolidação, e moradias em áreas não edificantes, como as de preservação permanente sobre a nascente e várzea do córrego.

\section{Planejamento habitacional e urbano integrado em cenário de contingenciamento de recursos}

O conjunto de experiências ora relatado ilustra a atuação de uma prefeitura empenhada em enfrentar sua precariedade habitacional. A conjuntura favorável quanto à disponibilidade financeira permitiu que o ente local fosse beneficiado com recursos federais consideráveis, materializados em diferentes ações. Estas, no entanto, só foram possíveis graças aos esforços prévios de planejamento habitacional. De fato, as necessidades habitacionais de vários municípios brasileiros só podem ser equacionadas com planejamento, que considere as necessidades fundiárias, de construção de moradias e de implantação de infraestrutura nas áreas carentes, bem como dependem da perenidade dos recursos financeiros em curto, médio e longo prazo. 
Em 2016, a revisão do Plano Diretor institui pela primeira vez as ZEIS no município, mais um passo para viabilizar a regularização fundiária das áreas que já estavam em processo de regularização urbanística. Este marco cria condições para finalizar as intervenções de Vila Ana e Jardim Nascente. Por outro lado, ainda falta muito para considerar os Jardins São Camilo e Novo Horizonte urbanizados. Estes demandam recursos adicionais que, por ora, não estão disponíveis, uma vez que o último lote do PAC II - Urbanização de Assentamentos Precários foi em 2013/14 e, até o momento, nada indica que será retomado.

\section{Agradecimentos}

As autoras agradecem aos técnicos da FUMAS que forneceram dados e informações sobre os núcleos estudados; aos professores Felipe de Souza Noto e Jonathas Magalhães Pereira da Silva pelos comentários e aos alunos, Dariane S. S. Silva (UNIP Jundiai), João Vencigueri (UNIP Jundiai) e Sarah Monteferrante (PUC Campinas) que colaboraram na confecção dos mapas.

\section{Referências:}

DENALDI, Rosana. Políticas de urbanização de favelas: evolução e impasses. Tese de doutorado - Faculdade de arquitetura e urbanismo da Universidade de São Paulo. São Paulo. 229p. 2003.

JUNDIAÍ. FUMAS. Prefeitura de Jundiaí (Org.). Produto 3.3 - Diagnóstico do Setor Habitacional. In:
JUNDIAÍ. Demacamp. Prefeitura de Jundiaí (Org.). PLHIS - Plano Local de Habitação de Interesse Social. Jundiaí: Prefeitura de Jundiaí, 2015, p. $1-251$.

OLIVEIRA, Natália Pereira de. Produção de Habitação e Desigualdades Socioespaciais: Perspectiva Crítica da "Urbanização Jardim Novo Horizonte", Jundiaí-SP. XI-Encontro Nacional da ANPEGE, Presidente Prudente, São Paulo, SP, 09 a 12 Outubro de 2015.

PEREIRA, Rodrigo Mendes: Dilemas da gestão pública habitacional: entre a gestão democrática e justa e a lógica financeira e privada, no contexto da cidade de Jundiaí-SP: Editora In House, 2016.

FUNDAÇÃO MUNICIPAL DE ASSISTENCIA SOCIAL, 2018. Disponível em: https://fumas.jundiai. sp.gov.br/institucional/atuacao. Acesso em 10 mai 2018.

INTITUTO BRASILEIRO DE GEOGRAFIA E ESTATISTICA. Cidades: Jundiaí. Disponível em: www. cidades.ibge.gov.br/brasil/sp/jundiai/panorama. Acesso em 10 mai 2018.

JUNDIAÍ. Lei n 8683, de 07 de julho de 2016. Plano Diretor do Município de Jundiaí. Jundiaí, 2016. Disponível em: <http://planodiretor.jundiai.sp.gov. br/lei-8683-2016/>. Acesso em: 02 out. 2017. 